\title{
Measuring Quality of Preventive Health and Safety Services
}

\author{
Fatih Yilmaz \\ Associate Professor, Department of Labour Economics and Industrial Relations, Bandirma Onyedi Eylul University, \\ Balikesir, Turkey. E-mail: fatihyilmaz@bandirma.edu.tr
}

Project Management

Received July 6, 2021; revised December 9, 2021; accepted December 9, 2021

Available online December 27, 2021

\begin{abstract}
In this research, the Servperf method is used to analyze the quality of health and safety services. The main purpose of this article is to determine the quality level of preventive health and safety services provided in the workplaces within the framework of the perception of the employees who benefit from these services. The questionnaire prepared in accordance with the Servperf method was applied to 412 employees working in various sectors, and the results were classified according to age, gender, education level, sector, and the way of providing (internal \& external) services. Descriptive statistics were used in the evaluation of results. The total perceived Servperf score of the health and safety services was 2.84, medium level. As the age and education level of the employees increases, the satisfaction level and Servperf scores of the service quality decrease. The satisfaction score of the construction workers is significantly lower than the other sectors. Satisfaction levels of employees in the workplaces where services are provided internally are higher than those of the workplaces offering external sources. Despite legal regulations related to preventive health and safety services, accidents have not decreased in Turkey. The quality of the service provided by external health and safety units is significantly low. Competition arising from the marketization of occupational health and safety services reduces the quality of the service provided. For these reasons, the number of research aimed at determining the quality of these services should be increased both in Turkey and in the world.
\end{abstract}

Keywords: Safety, service quality, servperf, health and safety, perceived quality.

Copyright $@$ Journal of Engineering, Project, and Production Management (EPPM-Journal).

DOI 10.32738/JEPPM-2022-0009

\section{Introduction}

In recent years, the service sector has been growing rapidly in the world, and the place of the service sector in the economy is increasing. The service sector is also growing rapidly in Turkey. Improving the quality of the service sector and measuring the service quality will be one of the most important challenges in the future.

Many methods have been developed to determine service quality. The most used methods for assessing the quality of service are Servqual and Servperf. The latter was proposed by Cronin and Taylor (1992) as a better alternative to the Servqual method developed previously by Parasuraman et al. (1988). Cronin and Taylor (1992) argued that determining the customer's quality expectation would not be meaningful if the customer did not recognize the company. Instead of revealing the difference between perceived service quality and expected service quality, they suggested that using a "performance" criterion based on customer satisfaction perception is a more accurate approach in measuring service quality. Thus, the number of dimensions in the Servperf method was reduced from 44 to 22. They also argued that the Servperf method, based on quality performance measurement consisting of perceived service quality, was easier and more successful in measuring service quality both theoretically and empirically.

However, there is still no consensus on which method is better in the literature. Both scales are considered applicable. Although various statistical studies have been conducted on the validity and reliability of the dimensions used in the quality measurement of both methods, different opinions have emerged. In addition to the studies suggesting that the dimensions of both methods are valid and reliable, there are also studies that determine that the Servperf method is statistically more powerful in measuring the quality of service (Jain and Gupta, 2004; Bulbul and Demirer, 2008; Angur et al., 1999; Armstrong et al., 1997).

Servperf method has been used in many service areas. However, there are few studies on measuring the quality of occupational health and safety $(\mathrm{OH} \& \mathrm{~S})$ services. In Turkey, the externalization of compulsory OH\&S services has increased in recent years. Sub-contracting these services from external OH\&S service providers is preferred by enterprises due to its many advantages (e.g., reduction of documentation and labor costs, transfer of responsibility). In Turkey, organizations offering these services are commercial enterprises. However, there is not enough quantitative study on the quality and adequacy of 
the OH\&S services provided by these external organizations. In addition, an occupational accident due to insufficient services may result in injury or death of employees. Therefore, it is important to use existing methods and to develop new methods for measuring the quality of services.

The obligation of providing OH\&S services entered into force in 2003 with the 4857 Act. in Turkey. With the OH\&S Act, which entered into force in 2012, this obligation was extended to cover all workplaces. Employers are entitled to perform these services on their own, or by purchasing services from external OH\&S providers. Following this obligation, OH\&S services were largely externalized and commercialized. In addition, the quality of these services, both the firms and their experts have started to be discussed. Therefore, measuring service quality has become important in the OH\&S field as well.

In this article, Servperf, which is a frequently used method for determining the quality of service, has been adapted to $\mathrm{OH} \& \mathrm{~S}$. The main objective of the article is to evaluate the quality level of preventive $O H \& S$ services and the variables that affect the quality from the perspective of the employees who benefit from these services. Another objective of the article is to determine whether there is a difference between the quality level of external OH\&S services and internal services. Perceived responses of employees in various sectors related to the quality of services provided in the workplace were collected, classified, graded, and analyzed with a questionnaire prepared in accordance with the Servperf method. The questionnaire was applied to 412 employees in various sectors. The distribution of the perceived $\mathrm{OH} \& \mathrm{~S}$ service quality by the employees' age, gender, education level, sector, and the way of providing OH\&S services (externalinternal) was analyzed and presented in consolidated tables.

\section{Literature Review}

Quality, which is generally defined as conformity to expectations, is an important element for all manufacturing and service companies. Especially because of its distinctive features such as synchronism in production and consumption, instability (no storage), variability (heterogeneity), and abstractness, quality of service is difficult to measure. However, it is also an important issue (Kotler, 1997). In addition to these characteristics, the behavior and characteristics of service providers and beneficiaries lead to more relative results in terms of measuring and evaluating the quality of services (Buyukkeklik et al., 2014).

Numerous models and scales have been proposed by different authors in the literature to measure service quality. The most widely accepted models are the Servqual model recommended by Parasuraman et al. (1988) and the Servperf model proposed by Cronin and Taylor (1992).

The Servperf model argues that quality of service is a function of performance (customer perception). The Servperf scale measures the customer's perception of service quality with five main dimensions and their sub-22 dimensions. These five main dimensions are tangibility, reliability, responsiveness, assurance, and empathy.

Although the Servqual method is used more frequently in published studies, it has been also used in many studies. It has been tested for reliability and validity in many service areas such as finance, transportation, IT, education, healthcare, and hospitals (Landrum et al., 2007; Wu and Cheng, 2013; Leong et al., 2015; Martins et al., 2015; Fragoso and Espinoza, 2017; Lee and Kim, 2014; Lowry and Wilson, 2016; Morton et al., 2016; Margaritis et al., 2012; Lupo, 2015; Oña et al., 2014; Namin, 2017; Landrum et al., 2010). However, there is no study in the literature that evaluates $\mathrm{OH} \& \mathrm{~S}$ service quality with the Servperf method.

Very few attempts have been conducted specifically on OH\&S service quality assessment. Servqual method was used in these several studies. Sakhvidi et al. (2016) carried out a Servqual-based study to examine the quality gap of occupational health services in an oil and gas company of Iran (Sakhvidi et al., 2016). A cross-sectional study was conducted between March 2013 and April 2014 in Isfahan, Iran. In conclusion of this study, they revealed a negative quality gap in Servqual and its all dimensions. They observed the highest and the least gap in empathy and reliability dimensions, respectively. Saadon et al. (2015) carried out a study integrating the Kano model and Servqual to improve training opportunities in OH\&S. Up till now, no other study has been found related to service quality dimensions of employee's point of view. In Turkey, Demir et al. (2018) used the Servqual method to determine the quality of $\mathrm{OH} \& \mathrm{~S}$ services. However, this survey was conducted with a questionnaire applied to the occupational safety experts, not the workers.

In another similar study, Buyukozkan et al. (2011) evaluated the quality of health care services in Turkey with the integrated Servqual-Fuzzy AHP. In another study in the health sector, health services were examined by the Servperf method and customer satisfaction and loyalty dimensions were included in addition to 22 dimensions (Songur et al., 2017). In another study similar to this one, Meesala and Paul (2018) examined service quality in hospitals with the Servperf method and compared the results by adding 4 more questions to determine patient satisfaction and loyalty in the survey.

However, Servperf has not been yet applied to OH\&S service quality evaluation. In this study, we adapted the questionnaire of Cronin and Taylor to the $\mathrm{OH} \& \mathrm{~S}$ area. In this study, we used a modified form of Servperf dimensions and presented a different point of view by providing the participation of 412 employees from different sectors.

\section{Research Methodology}

\subsection{Research Model and Analysis Process}

The research model was modified in accordance with the objectives of the study. Firstly, the service quality dimensions of $\mathrm{OH} \& \mathrm{~S}$ service providers were determined to evaluate the service quality perceived by employees and the quality performance of $\mathrm{OH} \& \mathrm{~S}$ service providers. Perceived service quality in the research model was evaluated by the Servperf scale consisting of 5 main and 22 sub-dimensions, and the total Servperf score was calculated. In addition, the participants were asked four more questions about satisfaction level, and loyalty (whether they would like to get OH\&S service in the same workplace again), and the results were compared with the Servperf scores.

Research and analysis were outlined as follows: 
(1) Descriptive dimensions of $\mathrm{OH} \& \mathrm{~S}$ service quality were identified.

(2) The questions prepared in accordance with the objectives of the study were adapted to the Servperf method. The questionnaire form was designed according to the dimensions of the method

(3) The questionnaire was applied to 412 employees in the service, manufacturing, and construction sectors.

(4) Collected data were transferred to SPSS 24 program and validity, and reliability analyzes were performed.

(5) Data were analyzed with descriptive statistics as follows:

- The data about the participant profile and the mean Servperf scores of all dimensions were calculated and total Servperf, satisfaction, and loyalty scores were calculated.

- The mean scores of Servperf, satisfaction and loyalty were calculated by age, gender, education level, sector, and how the workplace performs OH\&S services.

- The importance weights of the main dimensions were determined.

- Calculated data were prepared and analyzed in consolidated tables.

\subsection{Data Collection Method}

Data were collected through a standard questionnaire and face-to-face interviews. The questionnaire was applied to 412 employees working in various sectors. $20.6 \%$ of 2000 workers who were asked whether they wanted to participate in the survey answered the questionnaire.

The questionnaire consists of 3 sections. In the first section, the participants were asked to provide personal information, and in the second section, the service quality perceptions of the employees were measured by using the Servperf scale, which was adapted to the workers benefiting from $\mathrm{OH} \& \mathrm{~S}$ services. In the third part, questions about determining customer satisfaction and repurchase behavior (loyalty) were included.

The criteria and sub-criteria (dimensions and items) that measure service quality, customer satisfaction, and repurchase behavior are presented in the questionnaire (table 2). All dimensions in the survey are prepared by considering the legal regulations in Turkey within the scope of protective-preventive $\mathrm{OH} \& \mathrm{~S}$ services.

A five-point Likert scale was used to scale all the criteria in the questionnaire. Participants were asked to score each of the OH\&S quality dimensions in the questionnaire between 1-5.

\section{Validity and reliability analysis}

The questionnaire was applied to employees and in different sectors to test validity and reliability. In the study, a Cronbach's Alpha analysis is used to reveal the reliability of the Servperf model benefiting from IBM SPSS statistics 24. Cronbach's Alpha analysis enables the determination of the internal homogeneity of a group of variables with an alpha coefficient. The alpha coefficient measures an existing internal correlation between groups of variables. If the alpha coefficient is between 0 and 0.4 (excluding), the scale is unreliable. If it is between 0.4-0.6 (excluding), $0.6-0.8$ (excluding), and $0.8-1$, the scale is low reliability, high reliability, and very high reliability, respectively (Ozdamar, 1999).

The results of the reliability analysis are shown in Table 1 and it's seen that Cronbach Alpha coefficient values are highly reliable for all dimensions and for total satisfaction and loyalty scores data. The reliability value of all survey responses was 0.94 . In this case, it is possible to say that the reliability is very high for overall questionnaire data.

Table 1. Results of Cronbach Alpha test score for dimensions

\begin{tabular}{lc}
\hline Dimensions & Score \\
\hline Items/dimensions & 24 \\
Sum of all dimension variances & 20.94 \\
Variances of total scores & 223.32 \\
Chronbach's alpha $(\alpha)$ & 0.94 \\
\hline
\end{tabular}

\section{Results and Discussion}

Mean scores for all dimensions and total Servperf score are presented in table 2 . The total perceived service quality score of the employees was (2.84). The total quality score was found to be at the average level. The lowest quality score was (2.58) in the 4th dimension (working environment measurements (noise, gas, dust, etc.) are made on time). This low result is followed by the 22 nd dimension with (2.68) points (there are awards and penalties in $\mathrm{OH} \& \mathrm{~S}$ issues in the workplace) and the 5 th dimension with (2.73) points (employer monitors the $\mathrm{OH} \& \mathrm{~S}$ services and fulfils the expectations of the employees on time).

$42.96 \%$ of the employees are in the $26-35$ age group. $77.91 \%$ of the respondents were male and $35.92 \%$ were educated at high school level. $46.11 \%$ of the employees work in the service industry and $39.8 \%$ work in the manufacturing sector. As the age and education level of the employee's increases, the satisfaction level (Servperf scores) of the OH\&S services decreases.

While the scores of other age groups were close to each other, a significant difference was observed especially in the $45+$ age group. As the employee's age and experience increase, it appears that their expectations about OH\&S services increase in parallel with his / her experience in OH\&S. The quality perception score of university graduates regarding $\mathrm{OH} \& \mathrm{~S}$ services are lower than others.

According to the distribution of Servperf scores by sector, satisfaction score of employees in construction sector is significantly lower than other sectors. It should not be ignored that $46 \%$ of the employees participating in the survey work in the larger corporate firms in the service industry such as airlines, gas distribution, and public employees. In these firms, the OH\&S risks are less, but $\mathrm{OH} \& \mathrm{~S}$ services are relatively high quality. Lower scores are likely to be observed when the survey is applied to workers in SMEs and in more severe and hazardous workplaces such as construction and mining. In Turkey, $98 \%$ of workplaces are small and medium-sized. SMEs have higher risks in terms of $\mathrm{OH} \& \mathrm{~S}$ and $65 \%$ of occupational accidents occur in SMEs. The financial capabilities of SMEs are weaker than large firms. They cannot allocate enough money and time for the assessment of $\mathrm{OH} \& \mathrm{~S}$ risks and measures to be taken against accidents. 
Table 2. Overall Servperf score statistics about perceived quality of OH\&S services

\begin{tabular}{cccc}
\hline Dimension-item No. & N & $\begin{array}{c}\text { Mean value of } \\
\text { perceived } \\
\text { quality scores }\end{array}$ & $\begin{array}{c}\text { Standard deviation } \\
\text { deviances }\end{array}$ \\
\hline
\end{tabular}

Tangibility (working environment elements)

D1. Workplace has safe vehicle-equipment and technology

D2. Working environment of the workplace is suitable for $\mathrm{OH} \& \mathrm{~S}$.

$\begin{array}{llll}412 & 2.77 & 0.93 & 0.87 \\ 412 & 2.92 & 0.95 & 0.90 \\ 412 & 2.58 & 0.99 & 0.99\end{array}$

D4. Working environment measurements (noise, gas, dust, etc.) are made on time

\section{Reliability}

D5. The employer monitors the OH\&S services on time.

D6. The employer acts with a solution-oriented approach to employee health and safety problems

D7. Employer performs OH\&S services in a timely and appropriate manner (internal or external)

D8. Employees are informed in a timely manner with regard to preventive measures against hazards and risks.

D9. The near-misses are immediately examined and preventive measures are taken to prevent accidents.

\section{Responsiveness}

D10. The employer conducts training and practices on $\mathrm{OH} \& \mathrm{~S}$ issues in a timely manner.

D11. Risk assessment is carried out quickly in case of machine, equipment, work and workplace changes

D12. The employer is always willing to stand by and support employees in matters related to $\mathrm{OH} \& \mathrm{~S}$

D13. The employer spends enough time to meet the demands of employees on $\mathrm{OH} \& \mathrm{~S}$ issues

\section{Assurance (safety)}

D14. Employees are informed about the risks of chemical materials used in the workplace

D15. Employees are informed about work instructions, procedures, and legal regulations

D16. There is an emergency plan for Fire and Emergency Situations and employees are informed about these issues.

D17. PPE used in the workplace are suitable for employees and adequate information is provided

\section{Empathy}

D18. The employer endeavors to improve the knowledge and experience of employees regarding $\mathrm{OH} \& \mathrm{~S}$.

D19. Employer arranges working hours in accordance with the legislation

D20. The employer considers the complaints of employees about $\mathrm{OH} \& \mathrm{~S}$ services

D21. The employer makes improvements in matters related to $\mathrm{OH} \& \mathrm{~S}$. 
Table 2. Overall Servperf score statistics about perceived quality of OH\&S services (continued)

\begin{tabular}{|c|c|c|c|c|}
\hline Dimension-item No. & $\mathbf{N}$ & $\begin{array}{c}\text { Mean value of } \\
\text { perceived } \\
\text { quality scores }\end{array}$ & $\begin{array}{l}\text { Standard } \\
\text { deviation }\end{array}$ & Variances \\
\hline \multicolumn{5}{|l|}{ Consumer-employee satisfaction } \\
\hline $\begin{array}{l}\text { S1. I am satisfied with the OH\&S services of the company I } \\
\text { work for }\end{array}$ & 412 & 2.89 & 0.84 & 0.70 \\
\hline $\begin{array}{l}\text { S2. My workplace provides OH\&S services beyond my } \\
\text { expectations }\end{array}$ & 412 & 2.79 & 0.96 & 0.92 \\
\hline \multicolumn{5}{|l|}{ Repurchase intention-loyalty } \\
\hline $\begin{array}{l}\text { L1. I recommend my company to my friends in terms of } \\
\text { OH\&S }\end{array}$ & 412 & 2.98 & 0.86 & 0.74 \\
\hline $\begin{array}{l}\text { L2. In terms of OH\&S conditions, I would consider working } \\
\text { in this company again in the future }\end{array}$ & 412 & 3.03 & 0.83 & 0.69 \\
\hline $\begin{array}{l}\text { Mean value of all dimensions scores (overall perceived } \\
\text { quality score) }\end{array}$ & & 2.84 & & \\
\hline Mean value of employee satisfaction scores & & 2.84 & & \\
\hline Mean value of repurchase intention-loyalty scores & & 3.00 & & \\
\hline
\end{tabular}

Table 3. Overall Servperf scores by age, gender, education level and sectors

\begin{tabular}{|c|c|c|c|c|c|}
\hline & $\mathbf{F}$ & $\%$ & $\begin{array}{c}\text { Mean value of } \\
\text { perceived quality scores } \\
\text { of all dimensions }\end{array}$ & $\begin{array}{c}\text { Mean value of } \\
\text { employee } \\
\text { satisfaction scores }\end{array}$ & $\begin{array}{c}\text { Mean value of } \\
\text { repurchase intention- } \\
\text { loyalty scores }\end{array}$ \\
\hline \multicolumn{6}{|l|}{ Age group } \\
\hline $18-25$ & 62 & $15 . \%$ & 2.84 & 2.84 & 3.00 \\
\hline $26-35$ & 177 & $42.9 \%$ & 2.84 & 2.84 & 3.00 \\
\hline $36-45$ & 120 & $29.1 \%$ & 2.84 & 2.84 & 3.00 \\
\hline $45+$ & 53 & $12.8 \%$ & 2.78 & 2.74 & 2.93 \\
\hline \multicolumn{6}{|l|}{ Gender } \\
\hline Female & 91 & $22 \%$ & 2.85 & 2.85 & 3.01 \\
\hline Male & 321 & $77.9 \%$ & 2.84 & 2.84 & 3.00 \\
\hline \multicolumn{6}{|l|}{ Education } \\
\hline Primary School & 53 & $12.8 \%$ & 2.82 & 2.79 & 3.00 \\
\hline Secondary School & 67 & $16.2 \%$ & 2.84 & 2.84 & 3.01 \\
\hline High School & 148 & $35.9 \%$ & 2.84 & 2.84 & 3.00 \\
\hline Vocational School & 60 & $14.5 \%$ & 2.84 & 2.84 & 3.00 \\
\hline Graduate & 84 & $20.3 \%$ & 2.78 & 2.73 & 2.91 \\
\hline \multicolumn{6}{|l|}{ Sector } \\
\hline Service & 190 & $46.1 \%$ & 2.81 & 2.78 & 2.99 \\
\hline Manufacturing & 164 & $39.8 \%$ & 2.84 & 2.84 & 3.00 \\
\hline Construction & 58 & $14 \%$ & 2.69 & 2.68 & 2.76 \\
\hline
\end{tabular}

The satisfaction level of employees in workplaces that provide internal OH\&S services is slightly higher compared to the workplaces that purchase services from external OH\&S providers. The quality of OH\&S service perceived by employees is not good either way (Table 4).

The weights of the main dimensions were evaluated over 100 points. The total mean value and percentages of the main dimensions are presented in Table 5. According to the results, the average quality scores and weighted percentages of all main dimensions are close to each other. Here, with the highest mean value of $3.92(20.43 \%)$, "assurance" was achieved as the most important dimension according to the viewpoints of employees'. The least important dimension was the "tangibility" dimension with $3,78(\% 19.72)$ points. 
Table 4. Distribution of Servperf scores according to the internal and external OHS services

\begin{tabular}{lccccc}
\hline & F & $\%$ & $\begin{array}{c}\text { Mean value of } \\
\text { perceived quality } \\
\text { scores of all dimensions }\end{array}$ & $\begin{array}{c}\text { Mean value of } \\
\text { satisfaction } \\
\text { scores }\end{array}$ & $\begin{array}{c}\text { Mean value } \\
\text { of loyalty } \\
\text { scores }\end{array}$ \\
\hline $\begin{array}{l}\text { Workplaces purchasing OH\&S } \\
\text { service from external service units }\end{array}$ & 214 & $56.02 \%$ & 2.78 & 2.73 & 2.83 \\
$\begin{array}{l}\text { Workplaces providing internal } \\
\text { OHS services }\end{array}$ & 168 & $43.98 \%$ & 2.89 & 2.96 & 3.17 \\
\hline
\end{tabular}

Table 5. Means and percentages of main dimensions

\begin{tabular}{lccc}
\hline & N & $\begin{array}{c}\text { Mean value of main } \\
\text { dimension }\end{array}$ & \% \\
\hline Tangible elements (working environment) & 412 & 3.78 & $19.72 \%$ \\
Reliability & 412 & 3.81 & $19.83 \%$ \\
Responsiveness & 412 & 3.84 & $20.00 \%$ \\
Assurance-safety assurance, safety instructions and educations & 412 & 3.92 & $20.43 \%$ \\
Empathy & 412 & 3.84 & $20.02 \%$ \\
\hline
\end{tabular}

\section{Conclusions}

In this research, the Servperf method, which is one of the most frequently used methods in the evaluation of service quality, has been applied in the OH\&S field. The questionnaire, which was prepared considering the compulsory dimensions of the method, was adapted to the OH\&S field. Data from 412 employees (representing a 20.6\% response rate) were classified and analyzed. The quality of OH\&S services was evaluated from the perspective of the employees, and it was found that the perception of quality in all the dimensions was average (medium satisfaction) according to the Servperf method.

As the age and education level of the employees increases, the satisfaction level (Servperf scores) of the $\mathrm{OH} \& \mathrm{~S}$ services decreases. While the scores of other age groups were close to each other, a significant difference was observed especially in the $45+$ age group. As the employee's age and experience increase, it appears that their expectations about $\mathrm{OH} \& \mathrm{~S}$ services increase in parallel with his / her experience in $\mathrm{OH} \& \mathrm{~S}$. The quality perception score of university graduates regarding OHS services are lower than others. According to the distribution of Servperf scores by sector, satisfaction score of employees in the construction sector is significantly lower than other sectors.

In addition, it was determined that the satisfaction level of employees at workplaces providing OH\&S services within the company is slightly higher than workplaces that purchase services from external OH\&S suppliers.

If similar research is conducted in high-risk and small workplaces, quality satisfaction scores may be even lower. 250000 occupational accidents occur every year in Turkey. As a result of these accidents, 1500 workers die, and around 3000-4000 workers are exposed to permanent disability. Preventive approaches based on risk assessment in Turkey have been adopted several years ago, legal regulations have been in place since the OH\&S Act (2012). The structure that will implement the legal regulations is the organization of protective and preventive $\mathrm{OH} \& \mathrm{~S}$ services. In this sense, the quality of $\mathrm{OH} \& \mathrm{~S}$ services is also very important in terms of preventing occupational accidents and reducing the loss of lives. Previously, OH\&S services were provided internally in all workplaces. However, following the legal regulations, almost all enterprises - except for large and very hazardous activities - tend to sub-contract (i.e., to purchase) OH\&S Services from external providers. All external organizations providing $\mathrm{OH} \& \mathrm{~S}$ services are commercial enterprises. In addition, many of these external $\mathrm{OH} \& \mathrm{~S}$ providers are insufficient in terms of infrastructure, finance, equipment, and expert personnel resources. This has led to discussions about the quality of OH\&S services. At this point, it is seen how important it is to empirically measure the quality level of protective-preventive $\mathrm{OH} \& \mathrm{~S}$ services provided internally or externally by the employer.

With the legal arrangements made in 2012, more workplaces and employees started to benefit from preventive OH\&S services. However, occupational accidents and diseases have not decreased in Turkey. The quality of the services provided by these units is also controversial. Competition arising from the marketization of $\mathrm{OH} \& \mathrm{~S}$ services reduces the quality of the service provided. In addition, these external service units are not sufficiently inspected by the state. For these reasons, the number of research aimed at determining the quality of $\mathrm{OH} \& \mathrm{~S}$ services should be increased both in Turkey and in the world.

This study was conducted with a small sample in a small number of firms. However, different results may be obtained when the study is applied more widely. Servperf method is a method that can be applied in OH\&S services, which is simple to implement, easy to understand, and interpretable. However, different methods may be applied, new methods may be developed, or the Servperf method may be further developed with different statistical methods. This study was carried out in order to help future studies.

\section{Acknowledgments}

No funds were received in this research. Special thanks to occupational safety experts Murat Kalsin, Banu Catmaz, 
Tugçe Yilmaz, Muhammet Topçu, Murat Cal, and Yilmaz Senogul for their contributions.

\section{References}

Angur, M.G., Nataraajan, R.J., and John, S. (1999). Service quality in the banking industry: an assessment in a developing economy. International Journal of Bank Marketing, 17(3), 116-123.

Armstrong, R.W., Mok, C., Go, F.M., and Chan, A. (1997). The importance of cross- cultural expectations in the measurement of service quality perceptions in the hotel industry. International Journal of Hospitality Management, 16(2), 181-190.

Bulbul, H. and Demirer, O. (2008). Hizmet kalitesi ölçüm modelleri servqual ve servperf' in karşılaştırmalı analizi [Comperative analysis of servqual and servperf]. Selçuk Univ Sos Bil Enst Dergisi, 20, 163-179.

Buyukkeklik, A., Ozoglu, B., and Bulbul, H. (2014). Kargo hizmet sağlayıcılarında kalitenin tüketici davranışına etkisi: bireysel tüketici araştırması [The effect of quality on consumer behavior in cargo service providers: individual consumer research]. Selcuk Universitesi Sosyal Bilimler Enst Dergisi, Special Issue for Dr. Mehmet YILDIZ, 33-43.

Buyukozkan, G., Ciftci, G., and Guleryuz, S. (2011). Strategic analysis of healthcare service quality using fuzzy AHP methodology. Expert Systems with Applications, 38(8): 9407-9424.

Cronin, J.J. and Taylor, S.A. (1992). Measuring service quality: a reexamination and extension. Journal of Markenting, 56(3), 55-68.

Demir, P., Gul, M., and Guneri, A.F. (2018). Evaluating occupational health and safety service quality by Servqual: a field survey study. Total Quality Management \& Business Excellence, 31, 524-541.

Fragoso, J.T. and Espinoza, I.L. (2017). Assessment of banking service quality perception using the Servperf model. Contaduría y Administración, 62, 1294-1316.

Jain, S.K. and Gupta, G. (2004). Measuring service quality: Servqual vs. Servperf scales. The Journal for Decision Maker, 29(2), 25-37.

Kotler, P. (1997). Marketing management, analysis, planning, implementation and control. New Jersey: Prentice Hall.

Landrum, H., Prybutok, V.R., and Zhang, X. (2007). A comparison of Magal's service quality instrument with Servperf. Information \& Management, 44, 104-113.

Landrum, H., Prybutok, V.R., and Zhang, X. (2010). The moderating effect of occupation on the perception of information services quality and success. Computers \& Industrial Engineering, 58, 133-142.

Lee, H. and Kim, C. (2014). Benchmarking of service quality with data envelopment analysis. Expert Systems with Applications, 41(8), 3761-3768.

Leong, L.Y., Hew, T.S., Lee, V.H., and Ooi K.B. (2015). An SEM-artificial-neural-network analysis of the relationships between Servperf, customer satisfaction and loyalty among low-cost and full-service airline. Expert Systems with Applications, 42(19), 6620-6634.

Lowry, P.B. and Wilson, D. (2016). Creating agile organizations through IT: The influence of internal IT service perceptions on IT service quality and IT agility. Journal of Strategic Information Systems, 25(3), 211226.

Lupo, T. (2015). Fuzzy Servperf model combined with ELECTRE III to comparatively evaluate service quality of international airports in Sicily. Journal of Air Transport Management, 42, 249-259.

Margaritis, E., Katharaki, and M., Katharakis, G. (2012). Exceeding parents' expectations in Ear-Nose-Throat outpatient facilities: The development and analysis of a questionnaire. Evaluation and Program Planning, 35(2), 246-255.

Martins, A.L., Carvalho, J.C., Ramos, T., and Fael, J. (2015). Assessing obsterics perceived service quality at a public hospital. Journal of Global Strategic Management, 8(1), $16-25$.

Meesala, A. and Paul, J. (2018). Service quality, consumer satisfaction and loyalty in hospitals: thinking for the future. Journal of Retailing and Consumer Services, 40, 261-269.

Morton, C., Caulfield, B., and Anable, J. (2016). Customer perceptions of quality of service in public transport: Evidence for bus transit in Scotland. Case Studies on Transport Policy, 4(3), 199-207.

Namin, A. (2017). Revisiting customers' perception of service quality in fast food restaurants. Journal of Retailing and Consumer Services, 34, 70-81.

Oña de, R., Eboli, L., and Mazzulla, G. (2014). Monitoring changes in transit service quality over time. Procedia Social and Behavioral Sciences, 111, 974 - 983.

Ozdamar, K. (1999). Statistical data analysis with packaged software. Eskişehir: Kaan Publications.

Parasuraman, A., Zeithaml, V.A., and Berry, L.L. (1988). SERVQUAL: a multiple-item scale for measuring consumer perceptions of services quality. Journal of Retailing, 64(1), 12-40.

Saadon, M.S., Mustafa, Z., and Kamarulzaman, K.Z. (2015). The integration of the Kano model and Servqual into the house of quality for developing occupational safety and health training program. In: Ab. Hamid K., Ono O., Bostamam A., Poh Ai Ling A. (eds) The Malaysia-Japan model on technology partnership. Springer: Tokyo.

Sakhvidi, M.J.Z., Zolfagharı, A., Mehrparvar, A.H., Sakhvidi, F.Z., Bahramı, M.A., Montazerolfaraj, R., and Mostaghac1, M. (2016). Quality assessment in an occupational health setting using Servqual instrument. International Journal of Occupational Hygiene, 8(1): $22-30$.

Songur, L., Turan, A. and Songur, G. (2017). The measurement service quality in the health sector by means of servperf scale: the example of Sereflikochisar state hospital. The Journal of International Social Research, 10(53), 807-819.

Turkish occupational health and safety act No.6331. (2012).

Wu, H.C. and Cheng, C.C. (2013). A hierarchical model of service quality in the airline industry. Journal of Hospitality and Tourism Management, 20, 13-22.

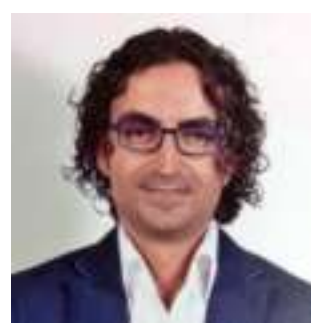

Dr. Fatih Yilmaz is an Associate Professor in the Department of Labour Economics and Industrial Relations at Bandirma Onyedi Eylul University in Balikesir, Turkey. His research interests are Safety, Risk Management, Construction Safety, and Social Policy. Dr. Yilmaz's publications can be found at http://orcid.org/0000-0001-8471-5633. His Researcher ID is AAC-9561-2019. 